\title{
Student Self Selection of Course Instructional Delivery Impacts Grade Attainment
}

\author{
Michael Seredycz* \\ Department of Sociology, MacEwan University, Canada
}

Submission: May 08, 2020; Published: June 05, 2020

"Corresponding author: Michael Seredycz, Assistant Professor, Department of Sociology, MacEwan University, 10700 104th Avenue Edmonton, Alberta, Canada

\section{Abstract}

The case study at a medium sized liberal arts university examined 303 undergraduate students enrolled in seven traditional face to face courses who were offered a choice to self-select into one of four blended modes of instruction. Students could select face to face (F2F) intervals of $90 \%$ (almost exclusively in the classroom) to 70\%, 30\% and 10\% (almost exclusively online with the exception of final exams). Multivariate models of analysis indicate that a student's self-selection of instructional delivery as well as race, semester course load, chosen major/minor fields of study, current GPA and flexibility of scheduling were directly related to grade attainment.

Keywords: Online; Blended; Hybrid; Learning; Instructional delivery; Face to face; F2F; Self-selection, Grade attainment

\section{Introduction}

Blended instruction has been adopted at an unprecedented level and continues to increase globally [1-3]. The COVID19 coronavirus led the World Health Organization (WHO) to report a global pandemic forcing many countries around the world to close colleges and universities [4]. Academic learning within post-secondary institutions has traditionally and predominantly been face to face (F2F) teaching instruction. This led colleges and universities across the world to scramble to offer traditionally F2F courses in an online environment.

Nearly 90\% of American colleges and universities reported online course offerings [5] however not all courses are offered online. Nearly seven in ten post-secondary institutions chief academic leaders across the United States reported online education was critical to their long term strategies [5] yet many of those Universities were seen scrambling during the COVID19 pandemic. As Harden [6] suggests, online learning has become the new mainstream tool in post-secondary education.

As college and university administrators begin to utilize and emphasize blended learning approaches, faculty members have been skeptical and resistant of their value and legitimacy. In an annual Sloan Consortium survey of chief academic officers, there is ample evidence to suggest that only one-third of faculty (between $28 \%$ and $34 \%$ over the last decade) felt there was value and merit within online courses [5]. In 2012, approximately $30 \%$ of chief academic officers reported that their faculty agreed that there was value and legitimacy of online courses while $57 \%$ of faculty had neutral opinions and 13\% disagreed [5]. These results would suggest that online coursework is still not identified as a valid and reliable method to instruct students by a majority of faculty. While context is required to explain why faculty may not be embracing online education, there is still an obvious conflict. Stereotypically, universities as an institution have been resistant to change, and faculty may not be any different. Moving from the status quo of teaching on a chalk board (now a white board) to power-point slides required time and instructional training. Evolving to WebCT, Blackboard, Desire to Learn and other software packages have required patience and computer literacy that require long term buy-in from faculty [6,7]. However, it appears that undergraduate students have embraced the change to distance education, online and blended courses $[8,9]$. As consumers of their own educational attainment, perhaps students should have the ability to choose and/or self-select their own method of instruction. This poses the question, should we be selling the approach of blended learning to facilitators of instruction or to the student consumers who purchase the instruction. 
Students want alternatives to traditional courses. The Sloan Consortium reports that the numbers of students who had taken at least one online course had increased from 1.2 million (2002) to nearly 6.7 million students in 2012 [5]. These numbers have exploded and continue to expand to simple course offerings to entire degree or diploma programs online. Online courses often go beyond simply flipping the classroom and/or using some web-based content [10]. In a more difficult and competitive global marketplace, undergraduate students have become the consumers of educational attainment rather than simply timid learners of yester year. Students want to know how their education will benefit them in a job/career placement (and when that can begin). With the significant increases in cost of living, expectation of employment, travel, tuition and books, students are examining the value for their dollar to determine not only which institution is right for them but also the availability of courses (Garrison, 2009). The ability to choose their courses and self-select into their chosen delivery method is often wanted and beneficial [11]. Therefore, providing more flexibility in time management [12] and offering more independent approaches to learning may reduce the likelihood of student failure and perhaps increase student satisfaction, recognizing that each student selects their own mode of instruction.

This study aims to reduce the hesitancy of instructors in developing blended and/or online courses while demonstrating viable alternatives, using student self-selection as a primer for the development of a unique, situational, contextual and individualized approach to post-secondary instructional delivery. While these initiatives have been explored in previous research, this case study provides a more simplistic test of blended learning alternatives and their impact on what students may view as success within a course, grade attainment.

\section{Literature Review}

Indicators of student success have generally been determined through the use of satisfaction surveys and/or learning performance measurements. Utilizing performance measurements such as examinations, research papers and/or presentations to measure verbal skills and/or dissemination is traditionally been utilized by instructors [13]. As such, traditional grading which includes scoring and associating learning with outcomes is perceived to be common place among course delivery and instruction. As consumers of learning, students perceive grades and the attainment of a good grade as a reflection of their work and effort to complete the tasks and performance measures [14] While these tasks and performance measures are unique by design by each instructor, students adapt to these courses and situational tasks. Grades and the attainment of a good grade (perceived as self-efficacy and unique to each student) is an adequate measure of a student's success [3].
The United States Department of Education [15] meta-analysis of over fifty studies concluded that blended or online courses on average will produce stronger student learning outcomes than face to face courses. This conclusion was based on $86 \%$ of studies that focused specifically on college and university students, predominantly at the undergraduate level [15], Interdisciplinary studies focused on kindergarten to grade twelve studies have found that blended learning has positive and often significant effects on student achievement $[16,17]$. As always evidence can be mixed as Tosun [18] and Wei et al. [19] reported.

Dziuban and his colleagues have found almost conclusively that online and blended instruction have significant merit as it relates to academic success. Dziuban et al. [20] reported at the University of Central Florida that the percentage of students who received a letter grade of $\mathrm{C}$ or above attained generally higher final grades in a blended environment than a traditional courses. Further examination by Dziuban et al. [20] examined blended learning of student success and grades by course modality finding that blended learning produced improved success rates for minority and non-minority students as well. When students were offered the opportunity to express effectiveness of their learning environments, students preferred blended learning. Zhao et al. examined a wide range of outcomes from achievement to motivational factors associated with outcomes finding that hybrid based learning instruction has some exceptional merits. Means et al. [21] report meta-analysis of online and blended learning on average produces stronger student learning outcomes than learning solely through face to face instruction.

A large study by Waldman \& Smith [22] contradicts some of the effects of blended instruction on student success when a student's final course mark was used as an outcome measurement. Their mixed methodological approach and more complex statistical analysis found a contradictory finding. Waldman \& Smith [22] reported that students who completed the course in the hybrid format achieved final grades that were 1.2\% lower than those who took the course in the traditional face to face format. This which appears high but was only 1 standard deviation when considering the standard deviation of final marks was 14.7\% (2013:13). Sex, age and a student's previous high school average were considered significant predictors of their final course mark. A student's domestic and/or full-time course load had no impact on their final grade. However, Walkman \& Smith [22] report that "the only variable that did moderate the effect of the instructional format was a student's cumulative grade point average [GPA] (2013 13). Students who had attained a lower standing GPA attained a modestly lower final mark when taking a course in the hybrid format. Students who had a current grade point average lower than a B letter grade had a slight reduction in their final course mark within blended learning. When sex, age, previous high school grade point average and current course load were controlled for within their additive model they were found to not be statistically 
significant. As they explain, "the probability of achieving a final grade of $\mathrm{C}$ or better was approximately $10 \%$ lower for students with low GPAs who took the hybrid course, but this difference disappears for students with high cumulative GPAs" (2013: 14). Despite those findings, nearly $80 \%$ of students reported interest in a combination of hybrid and traditional courses while nearly $60 \%$ reported they would take half of their courses in a blended format in the future (2013:18).

Cavanaugh \& Jacquemin [23] utilized data from over 5000 courses taught by over 100 faculty members and found that grade based learning outcomes could not be attributable to instructional delivery. Students with high GPA do better in online courses, while poor performing students have better grades in traditional classes than in online courses. The negligible difference was less than 0.07 GPA points on a four point scale (2015:8). The primary influence on individual course grades was student GPA. Students with higher GPAs were found to have attained better scores in online courses while struggling students attained lower grades compared to a face to face instructional delivery.

Boyle et al. [24] studied the impact of hybrid learning on 600 students by comparing a blended learning environment to a traditional learning environment. The aim of their project was to improve student success rates in learning to program. Their blending of course material and instruction increased module organization, tutorial support and online resources. Their findings indicated a "marked improvement in pass rates" at two postsecondary institutions [24]. Not only did students report a positive evaluation of the blended course instruction, the passing rate for students in the hybrid courses increased by $12 \%$ to $23 \%$, relative to the pass rate for students taking traditional classes taught the previous year [24]. A study by Kenney \& Newcombe [25] found similar results, that blended learning had higher average scores/ grades than non-blended learning environments.

A study by Bolsen et al. [26] added more complexity in ascertaining whether blended learning strategies were effective. Students self-selected into four sections (traditional, blended and online) of political science courses that were predetermined and randomly assigned to employ different pedagogies. Bolsen et al. [26] report that instructional delivery was significantly related to student academic engagement and performance (as well as civic educational outcomes). Therefore, employing different pedagogies and/or online learning platforms may benefit students. A study by Denoui \& Dodge [27] strengthen this argument. Denoni \& Dodge [27] examined the impact of Blackboard (web-based instructional platform) on grade attainment within courses in the discipline of psychology. In addition to unfettered access to syllabi, course notes, interactive demonstrations and handouts, audio and video recorded lectures were available. Findings suggest that there was a positive partial correlation between Blackboard usage and exam grades.

Within a graduate nursing course taught in both traditional and blended formats, Kumrow [28] reported that students in the blended sections had overall higher grades with a "help" seeking strategy correlated with higher grades. While adding independence, flexibility and convenience to blended instruction provides merit for students, As Kumrow [28] points out, while students still suggest blended courses are favorable, negative perceptions of blended courses could result in a need for hands on instruction, especially when content may not be suitable for online delivery [29]. Therefore, while there are positive perceptions of students interested in blended courses, instructors must be prepared to ensure act timely with immediate feedback $[14,30]$.

However, there is still ample evidence to suggest that blended learning has the same or no effect (versus traditional face to face courses) on grade attainment. While many studies have shown positive correlations between hybrid instruction and student achievement at both the undergraduate and graduate level, other studies have either shown no impact or a negative correlation. Parker \& Nelson [31] allowed for students to self-select into a format of one of three course sections (traditional, blended and online) with all three selections remaining consistent with one another. Their findings suggest that online learning is not systematically inferior to traditional classroom learning. Another study by Kwak et al. [32] had shown that even replacing few hours of a traditional statistics course with online material had a negative effect on final, full semester student grades. Therefore, it should be noted that not every course can simply translate into a blended or online offering [33,34].

This study seeks to integrate what we know, what we don't and what is promising with the previous research that has been conducted. Roscoe [35] compared hybrid and traditional format 300-level undergraduate courses within political science. Both classes completed the same performance measurements and findings suggest that academic performance and grades were not influenced by the mode of instruction (2008). A study by Riveria \& Rice [36] compared graduate students who enrolled in a traditional, online, and hybrid course. Their findings were similar to that of Roscoe [35] where instructional delivery was found to have a lessened effect of blended learning and exam grades. York [37] examined three modes of instructional delivery (traditional, blended and online) and found that there was no difference in terms of knowledge gain or student satisfaction. Their findings suggest that online instruction achieves outcomes comparable with the traditional format. This study utilizes a larger sample size as well as the promotion of choice within instructional deliverables to ascertain any differences with previous research. Choice offers each student (as the consumer of knowledge) not simply flexibility and convenience but also access. As such, studies do suggest that students would choose to attend about half of the face to face courses when choosing between attending lecture or accessing the lecture online [38,39].

Providing equal access to instruction is becoming a "critical need" [20] particularly if institutions begin to consider student self-selection and/or adopting more universal design approaches to assist all students across all communities. Providing each 
student the opportunity to learn in multiple instructional delivery modes using video lectures and similar outcomes ensures consistency across what Rasch \& Schnotz [40] denote as learning efficiency; appropriate time devoted to each learning outcome or performance measure. While students may be less aware of these learning efficiencies, they often complain of busy work where these learning outcomes are either not measured or could be inefficient. As such, the aim of the course (in its development) was to ensure learning efficiency was consistent and maintained as much as possible to a traditional face to face course. By remaining consistent with modes of instruction but simply offering more flexibility and independence of instruction [41], it preserves learning efficiency and potentially its effectiveness [42,43]. A study by Demirkol \& Kazu (2014) further suggest that blended and online courses can reduce disparities associated grade dispersion and gender, ethnic and racial demographics of students. Perhaps instructors may also want to re-assess what is in the best interests of the student when considering the usage, adoption or development of a blended or online program [34]. However, it is easy for instructors to be critical of hybrid or online learning environments.

\section{Methodology}

The 322 participants of this study were chosen from seven traditional undergraduate courses offered within a midwestern American liberal arts university. They registered for a 200-level criminology/ criminal justice course initially unaware of any instructional self-selection study. Twenty-two students were removed from the study having dropped or withdrawing from the course throughout the semester. Due to the small sample size of wirhdrawal it would be unwise to use this as a valid measurement. An additional nine students were removed from the study for not having completed survey instruments. Therefore, the sample size for the purpose of analysis was 303 participants.

The seven undergraduate courses were offered over a sixteenweek semester cycle encompassing 34 one-hour blocks of class time. The course was predicated on utilizing a text that could be offered in both print and online versions. Microsoft power point modules were also used to ensure that additional resources were included in the course to ensure the retention of key concepts, interconnectivity with the text and any outside resources. Students would be expected to read the required text for the course in addition to supplemental technical reports, peer reviewed articles and online audio-visual clips. Each course was designed to ensure consistency across performance measurements. Performance measures included three examinations $(75 \%$ of a final grade) and three assignments worth $10 \%, 5 \%$ and $10 \%$ respectfully. The three examinations were proctored in class and were similar in questions and rigor. Three assignments could easily be related to course materials and a student's ability to identify other valid online sources (technical reports and peer reviewed studies) to ensure connectivity and engagement to the text and course content. Assignments were designed with more emphasis on critical thinking and problem solving (associated within experiential and student-centered pedagogical approaches). Rubrics were clearly conceptualized and operationalized within an online environment with drop-box delivery systems. The study also attempted to alleviate concerns that online courses would require more time to grade engagement measurements. Therefore, no additional instructional time was allocated to an online delivery system that would not be present in a traditional course delivery. While significant time and energy was devoted into developing these instructional methods of delivery, no one group was asked to do more rigorous work than another group. This simplistic approach was adopted to demonstrate that instructors may not need to compromise outcomes when developing new types of instructional delivery that students could select. However, due to the simplicity of the study, there were some obvious limitations. Attendance and participation/ engagement would not be a measurable outcome. Students were offered discussion boards, discussion threads and online video conferencing as levels of peer engagement similar to that of a traditional classroom setting. However, these modes of engagement would not be used as performance measurements. Despite the lack of graded engagement, the use of office hours and/ or email for instructor feedback or assistance was still available. This study assumed that offering more immediate instructor feedback $[14,30]$ was more important than grading engagement as a performance measure.

On the first day of classes, students were asked to choose or self-select into one of four types of instructional delivery methods. This study conceptualized and operationalized four instructional delivery systems as developed by [44] and the Sloan Consortium [5] into different categories of hybrid/blended instructional delivery: replacement (90:\% F2F : 10\% Online), supplemental (70\% F2F : 30\% Online) and two emporium options - 30\% F2F : 70\% Online and 10\% Online : 90\% F2F. Students were offered these four options. Using [44] model, $90 \%$ of the course would be delivered face to face and 10\% online. Within this 90:10 option, $10 \%$ of course materials and assignment functions would be online with students able to interact with one another in class or through discussion boards. Over a sixteen-week semester with 34 instructional hours, 28 hours would be devoted to face to face lectures, 3 hours devoted to 3 examinations and 3 hours devoted to online learning. These three online classes would be devoted to written assignments where students could identify and utilize sources of information to supplement their written work. These classes were designed around both experiential and studentcentered learning strategies while also ensuring compliance in reading comprehension and retention of key concepts and themes [45].

The second option, designated as a 70:30 blended option, offered students $70 \%$ of the course within the classroom and $30 \%$ within an online environment. Within this 70:30 supplemental approach (inclusive of 34 instructional hours), 21 hours would be devoted for face to face lectures, 10 hours initially designated as face to face lectures would be substituted by 8 video-based 
lectures and 2 hours of independent online readings. Three hours were devoted to in class examinations. The 10 digital lecture recordings would be made available through Camtasia software within an online environment. Digital recordings of all instructor criminology/ criminal justice lectures allowed for its simple reintroduction at different intervals without revising content and/ or translation. Therefore, class-based discussions could still be utilized and implemented within an online environment [46-53].

Students could select a third option; denoted 30:70, where $30 \%$ of the course would be delivered face to face and a larger majority $(70 \%)$ would be offered within an online delivery environment. The emporium approach [44] offers students a replacement of face to face discussions with more online deliverables including more Camtasia lectures and collaborative peer discussions, if students want to remain engaged. This approach offered students more independence and flexibility outside the classroom. In terms of instructional delivery, 3 hours were devoted to in class examinations; 10 hours were allocated to instructional face to face lectures with 21 hours of original lecture time replaced with 19 hours of digital Camtasia lectures and 2 hours of independent readings.

To offer students even more selection, students were offered the choice of a 10:90 instructional delivery. Similar to a very traditional online delivery, $10 \%$ of the course would be delivered face to face and $90 \%$ of the course would be instructed within an online environment. This emporium model approach offered students the most discretion and flexibility in their schedule where 3 instructional hours were devoted to examinations, 3 hours for face to face discussions that were pertinent more to assignments and examinations whereas 28 hours of instruction was delivered online. Digital Camtasia lectures and tutorials were utilized to replace all face to face lectures while discussion boards and threads were also utilized as forms of engagement (but were not graded). While the inherent design of the course was to ensure that students were able to self-select and choose their instructional delivery, the study wanted to ensure that students were generally satisfied. Therefore, after the completion of the first exam (one month; 8 classes into the course), students could re-select an option that they initially had not chosen. This offered each student more flexibility if they felt the instructional delivery they first selected was incorrect. This buffet style approach [44] offered students the ultimate level of discretion of their own learning environment without revising any performance measures. This was also a component of the study to ascertain whether students would revise their original desired instructional method to something more useful for that individual student. In addition to selecting an instructional delivery model, students were asked to complete several surveys (pre-test and post-test) to attain more data for analysis. Furthermore, to ensure more validated measurement, students would consent to attaining valid measurements from the Registrar's Office.

\section{Findings}

As explained previously, the study sample began with 334 eligible students enrolled in seven 200-level criminology/ criminal justice courses within a liberal arts university in the midwestern United States. Thirty-one students were removed from the study for (i) having dropped or withdrawing from the course or not completing their self-administered surveys. Therefore, 303 students were used for the analysis of this study.

Table 1 below profiles the students and their self-selection and/or re-selection of instructional delivery. Students were offered their initial choice immediately but were also offered a choice to reselect approximately one month after their initial choice (at their first examination). As seen below, $45 \%$ of students preferred the 70:30 blended option; giving them more flexibility than the 90:10 traditional course $(24 \%)$ or the more online $30: 70$ blended $(20 \%)$ option. One in every ten students selected the almost entirely constructed course where $90 \%$ would be instructed online. However, when provided the opportunity, 10 students revised their initial choice and approximately half of students (48\%) selected the 70:30 option. All 10 students who initially chose less face to face engagement (90:10 or 30:70) selected options with more class time attributed to the class engagement. In all ten cases where students re-selected and/or revised their initial decision, they reported wanting more interaction with other students and/ or attain more detail in understanding key concepts and themes. It was clear that students chose an emporium approach (64\%) to a traditional $(25 \%)$ or almost solely online $(9 \%)$ instructional delivery. It should be noted that the revised selection options were used for further analysis.

Table 1: Student Self Selection: Initial and Revised instructional delivery.

\begin{tabular}{|c|c|c|c|c|}
\hline Variables & $\%$ & (n) & $\%$ & (n) \\
\hline Instructional Delivery & \multicolumn{3}{|c|}{ Initial } & \multicolumn{2}{|c|}{ Revised } \\
\hline $90: 10$ & $24.40 \%$ & $(74)$ & $24.80 \%$ & $(75)$ \\
\hline $70: 30$ & $45.3 \%$ & $(137)$ & $48.20 \%$ & $(146)$ \\
\hline $30: 70$ & $20.10 \%$ & $(61)$ & $18.20 \%$ & $(55)$ \\
\hline $10: 90$ & $10.20 \%$ & $(31)$ & $8.80 \%$ & $(27)$ \\
\hline
\end{tabular}

In addition to students selecting their instructional delivery, several variables of interest were collected using a survey instrument. Students were asked to complete a short open-ended self-administered questionnaire at the beginning of the course. Responses were relevant to establishing a baseline of data points to understand the profile of the sample. Responses of the variables of interest were coded to generate the appropriate values; as seen below in Table 2. 
Table 2: Student profile.

\begin{tabular}{|c|c|c|}
\hline Variables & $\%$ & (n) \\
\hline \multicolumn{3}{|l|}{ Age groups } \\
\hline 18 & $2.90 \%$ & (9) \\
\hline 19 & $48.20 \%$ & $(146)$ \\
\hline 20 & $30.40 \%$ & $(92)$ \\
\hline 21 & $10.90 \%$ & (33) \\
\hline $22+$ & $7.60 \%$ & (23) \\
\hline \multicolumn{3}{|l|}{ Sex } \\
\hline Male & $44.20 \%$ & $(134)$ \\
\hline Female & $55.80 \%$ & $(169)$ \\
\hline \multicolumn{3}{|l|}{ Race } \\
\hline White & $72.10 \%$ & $(218)$ \\
\hline Black & $24.20 \%$ & $(73)$ \\
\hline Asian & $2.00 \%$ & (6) \\
\hline Native American & $1.60 \%$ & (5) \\
\hline Other & $0.10 \%$ & (1) \\
\hline \multicolumn{3}{|l|}{ Ethnicity } \\
\hline Hispanic & $15.50 \%$ & $(47)$ \\
\hline Non-Hispanic & $84.50 \%$ & $(256)$ \\
\hline \multicolumn{3}{|c|}{ Computer proficiency/preparedness } \\
\hline Strongly agree & $94.40 \%$ & $(286)$ \\
\hline Agree & $2.90 \%$ & (9) \\
\hline Neutral & $1.00 \%$ & (3) \\
\hline Disagree & $1.70 \%$ & (5) \\
\hline Strongly disagree & $0 \%$ & $(0)$ \\
\hline \multicolumn{3}{|c|}{ Previous online course } \\
\hline Yes & $4.60 \%$ & (14) \\
\hline No & $95.40 \%$ & $(289)$ \\
\hline \multicolumn{3}{|c|}{ Previous blended course } \\
\hline Yes & $4.00 \%$ & (12) \\
\hline No & $96.00 \%$ & $(291)$ \\
\hline \multicolumn{3}{|c|}{ Grade attainment expectation } \\
\hline A & $35.30 \%$ & $(106)$ \\
\hline B & $45.70 \%$ & $(138)$ \\
\hline $\mathrm{C}$ & $18.90 \%$ & (57) \\
\hline $\mathrm{D} /$ pass & $0.10 \%$ & $(2)$ \\
\hline \multicolumn{3}{|c|}{ Flexibility of scheduling } \\
\hline Strongly agree & $17.20 \%$ & $(52)$ \\
\hline Agree & $59.80 \%$ & $(181)$ \\
\hline Neutral & $2.60 \%$ & (8) \\
\hline Disagree & $7.90 \%$ & $(24)$ \\
\hline Strongly disagree & $12.50 \%$ & $(38)$ \\
\hline
\end{tabular}

Table 2 examines the attitudes and expectations students reported while also selecting their instructional delivery. In terms of age, a significant majority (92\%) of students who participated in the study was generally 21 or under, Similar to the University demographics, women represented a larger percentage (55\%) of the students enrolled in the courses. Closely representative of the University's student body demographics, the majority of students self-identified as White (72\%) while a large concentration of students self-identified as Black and/or African American (24\%). Furthermore, those who identified as Hispanic were approximately $16 \%$ of the sample and also typical of the student body at the University where this study was conducted.

The pre-test questionnaire also asked students regarding their previous experience regarding blended and online coursework. When asked if students were computer proficient and/or prepared to take a course that was online and/or blended an astonishing $97 \%$ of students agreed or strongly agreed with the statement. Therefore, contrary to previous research that has been conducted, students felt that they were prepared for some form of online environment. Students reported overwhelmingly that they have never taken a solely online (95\%) and/or a blended learning (96\%) course in the past. Considering that most students were generally unaware of a blended or online course offering, they perceived that taking this option would not be an issue and that they felt prepared (in terms of computer literacy).

In an effort to measure grade attainment, the study chose to also examine grade expectations to further determine if expectations of a particular letter grade were consistent with the grade they achieved. This could be considered a measurement of self-efficacy and success. Prior to any coursework being presented, other than the syllabus, readings and materials online, 35\% of students in the sample felt that they could attain an A letter grade. However, the majority, approximately $45 \%$ of students expected to attain a B. Nearly two in ten students (19\%) reported that they were expecting a $\mathrm{C}$ in the course while two students reported that attaining a D or passing the course was their expectation. This variable could further be correlated with their final grade (as seen below).

In an effort to test motivation for grade attainment, the study asked students to reflect on whether flexibility and convenience was a motivating factor for selecting a particular form of course instruction. Three-quarters of students reported that they agreed $(60 \%)$ or strongly agreed $(17 \%)$ that flexibility and convenience of scheduling would have an impact on their decision. These findings would substantiate the literature as to why students may consider blended or online learning.

In addition to the pre-test variables of interest, students' data was also corroborated with more valid reporting measurements attained from the University Registrar. Table 3 outlines the validation measurements that were used to also generate variables of interest for further predictive analysis. 
Table 3: Validated measurements.

\begin{tabular}{|c|c|c|}
\hline Variables & \% & (n) \\
\hline Current courses enrolled & & \\
\hline Two & $5.60 \%$ & $(17)$ \\
\hline Three & $27.00 \%$ & $(82)$ \\
\hline Four & $58.80 \%$ & $(178)$ \\
\hline Five or more & $8.60 \%$ & $(26)$ \\
\hline Importance of the course & & \\
\hline Elective & $37.60 \%$ & $(114)$ \\
\hline Major/Minor & $62.40 \%$ & $(189)$ \\
\hline Current GPA range & & \\
\hline A & $13.80 \%$ & $(42)$ \\
\hline B & $43.60 \%$ & $(132)$ \\
\hline C & $30.70 \%$ & $(93)$ \\
\hline D & $9.60 \%$ & $(29)$ \\
\hline F/ Probationary & $2.30 \%$ & $(7)$ \\
\hline
\end{tabular}

Three additional validation measurements were utilized to attain current and accurate detail of students who were enrolled in the study. This accuracy rather than having students guess or hypothesize allowed for a more reliable measure. It appears through University records that a large majority of students were taking larger numbers of classes simultaneously. Less than $6 \%$ of the students were taking courses on a part time basis while $94 \%$ of students were taking three or more classes (considered a full time course load). Approximately $8 \%$ of the sample were taking the most courses allowed (without permission) at five courses within the same semester. The relative importance of the course was another variable of interest that is often not considered particularly pertinent in the literature. Perhaps students who are more likely to engage in a their designated career path (in this case criminology/ criminal justice) feel that face to face course work might be more ideal versus students who perceive the class as simply an elective (and/or perhaps a class they simply have to complete their liberal arts degree). A majority (62\%) of the students enrolled in the seven courses were utilizing the class as a chosen major or minor of their study while $38 \%$ of students were taking the class as an elective and/or general course (not having declared a major or minor in criminology/ criminal justice). A final variables of interest that is often self-reported is a student's grade point average, University records report that a large percentage of students $(74 \%)$ were in the grade point average (GPA) range of a $\mathrm{B}$ to $\mathrm{C}$. A lesser number of students had an A average (14\%) while one in ten students $(11 \%)$ were considered more high risk (having attained a D, F and/or probationary score).

As the course concluded, final grades were posted for students to attain further feedback. Final grade attainment was measured below, where percentages were afforded letter grades. Grades were skewed higher than the bell curve with a majority of students
(38\%) attaining a C grade while $46 \%$ of students were above a C and approximately $16 \%$ below the $\mathrm{C}$ grade with fourteen students failing the course (Table 4).

Table 4: Student grade attainment.

\begin{tabular}{|c|c|c|}
\hline Variables & $\mathbf{\%}$ & (n) \\
\hline Grade attainment & & \\
\hline A & $20.80 \%$ & $(63)$ \\
\hline B & $25.70 \%$ & $(78)$ \\
\hline C & $37.6 \%$ & $(114)$ \\
\hline D/pass & $11.20 \%$ & $(34)$ \\
\hline F & $4.60 \%$ & $(14)$ \\
\hline
\end{tabular}

If we consider a previously reported variable of grade expectation with grade attainment, it is simple to see that most students had relatively high expectations as compared to their final results. While approximately $35 \%$ of students in the sample felt that they could attain and anticipate an A letter grade in the course only $21 \%$ of students were able to attain the A. Furthermore, $45 \%$ of students expected to attain a B but only $26 \%$ completed the course with a B letter grade. While approximately $20 \%$ reported expecting a $\mathrm{C}$ in the course, over one-third (38\%) of students attained a C. Unfortunately, $11 \%$ of students attained a final grade of a $\mathrm{D}$ which did not allow them to attain the pre-requisite to take a 300-level course in criminology/ criminal justice and fourteen students failed the course with an F letter grade (which no one expected or anticipated).

A quick comparative bivariate analysis was completed to compare the difference in means between interval levels of selfselection and compared to grade attainment. As Table 5 suggests, there was a difference in means across all four intervals of selfselection instructional deliveries. It appears that students who enrolled in a 70:30 blended course had a slightly higher likelihood of attaining a higher grade on average as compared to all other forms of blended learning. However, it also appears that attending the most classes in a traditional format, 90:10 offered students the benefit of ensuring a passing grade. Perhaps the most striking difference within Table 5 is when students enrolled in the more online instructional offerings of 30:70 and 10:90 where mean scores dropped significantly as more students were likely to fail the course.

Table 5: Descriptive statistics of Instructional delivery on Grade attainment.

\begin{tabular}{|c|c|c|c|c|c|}
\hline Instructional Delivery & Cases & Min. & Max. & Mean & S.D. \\
\hline $90: 10$ & 75 & 52.5 & 91 & 78 & 12.45 \\
\hline $70: 30$ & 146 & 48 & 93 & 81.5 & 13.68 \\
\hline $30: 70$ & 55 & 46 & 90 & 72.5 & 18.21 \\
\hline $10: 90$ & 27 & 47 & 86 & 71 & 17.44 \\
\hline
\end{tabular}


Further multivariate analysis utilizing an ordinary least squares linear regression provided a stronger sense of predictability and/or causation of grade attainment. However, due to the lack of variance in responses meant removing several variables from the models below. Table 6 examines the predictive power of self-selection of instructional delivery and other factors that influence student grade attainment in the course. This linear regression model was found to be statistically significant $(.013$ with a confidence level of $95 \%$ with the $p<.05$ being significantly different than zero). Self-selection and seven variables were found to explain $38 \%$ of grade attainment based on a Nagelkerke R Square. The regression reported a Chi-square of 116.72 and a model -2 Log likelihood of 194.22 (with 8 degrees of freedom).

Table 6: Predicting student grade attainment.

\begin{tabular}{|c|c|c|c|}
\hline Variable & Beta & S.E & Sig. \\
\hline Age & 1.02 & 0.52 & 0.211 \\
\hline Sex (Men) & 0.23 & 0.19 & 0.319 \\
\hline Race (Non-White) & 0.44 & 0.27 & 0.422 \\
\hline Self-selection & 0.82 & 0.64 & $.003^{*}$ \\
\hline Flexibility/ convenience & 1.4 & 0.59 & $.001^{*}$ \\
\hline Current courses enrolled & 3.42 & 0.72 & 0.328 \\
\hline Course as major/minor & 1.97 & 0.42 & $.001^{*}$ \\
\hline GPA & 1.68 & 0.91 & 0.943 \\
\hline Constant & -3.09 & 0.85 & 0.229 \\
\hline
\end{tabular}

As Table 6 reports, three variables were found to be significant predictors of grade attainment. All factors considered, none of the sample's demographic variables were found to have any statistical significance nor did the number of courses a student had enrolled in. It would be expected that students who took more courses would have a higher likelihood of attaining a lesser grade however; the data does not suggest that this has occurred within the sample. Additionally, a student's current grade point average also had no statistical significant impact on their final grade attainment. However, it does appear that the most significant factor in predicting grade attainment was whether the course was one which was required for a student's major or minor area of study (versus an elective) to attain their four year degree. This might suggest that students who are more engaged with the course as a result of their current career path are more likely to attain a higher final grade. Based on the Beta coefficient, it appears that the second most significant factor in predicting a higher grade attainment was those who reported a need for flexibility and convenience in their workload. While this certainly was correlated with self-selection, no cases of multicollinearity were present. No cases were removed from the analysis when the variance inflation factor (VIF >4) and tolerance (TOL) levels of 2.0 or above were controlled for. A student's choice of instructional delivery was also found to be statistically significant and related to grade attainment. It appears that while this variable was not the strongest predictor of the variables, it does suggest that the lower the level of blended learning which takes place (either at the 90:10 or 70:30 instructional delivery) the higher the grade students (in the sample) will have attained in the course.

To attain more information on grade attainment, success could also be measured by whether grade expectations (reported at the beginning of the course) were met by the attainment of that particular grade. If I student anticipated a B, Did they attain a B? If students reported a grade expectation and successfully attained that same grade, it would be recoded as a dummy variable of 1 (less likely to be predicted). On the other hand, if a student reported a grade expectation and did not successfully meet their goal it would be coded as 0 (or more likely to be reported). The logistic regression below (within Table 7) examines the predictive power of the same variables of interest with a key difference where self-selection of instructional delivery was recoded in reverse to ensure/ attain more information on the variable itself. This linear regression model was found to be statistically significant $(.001$ with a confidence level of $95 \%$ with the $p<.05$ being significantly different than zero). Self-selection and seven variables were found to explain $41 \%$ of a matched grade expectation and attainment based on a Nagelkerke R Square. The regression reported a Chisquare of 148.89 and a model -2 Log likelihood of 206.13 (with 8 degrees of freedom). Controlling for multicollinearity (VIF $>4$ and TOL >2.0), eight cases were removed from the analysis.

Table 7: Predicting the matching of student grade expectations with attainment.

\begin{tabular}{|c|c|c|c|}
\hline Variable & Beta & S.E & Sig. \\
\hline Age & 0.42 & 0.39 & 0.843 \\
\hline Sex (Men) & 0.67 & 0.61 & 0.499 \\
\hline Race (Non-White) & 0.19 & 0.12 & $.028^{*}$ \\
\hline Self-selection (reverse coding) & -0.95 & 0.34 & $.001^{*}$ \\
\hline Flexibility/ convenience & 0.46 & 0.32 & $.001^{*}$ \\
\hline Current courses enrolled & 1.12 & 0.64 & $.042^{*}$ \\
\hline Course as major/minor & 0.82 & 0.39 & $.039^{*}$ \\
\hline GPA & 0.75 & 0.51 & $.032^{*}$ \\
\hline Constant & 0.74 & 0.71 & 0.843 \\
\hline
\end{tabular}

Attaining a differing measurement for success was certainly useful in ascertaining whether students were able to meet their goals of the course as it relates to matching their expectation to an attained grade. As seen above in Table 7, the age and sex of the students remains insignificant in the model however, race becomes a significant variable. While only being a relatively small predictor of the model, it appears that race (those who selfreported as non-white) could more accurately predict their final grade that was attained in the course. Furthermore, it appears, that when reverse coded, those students who attain a higher level of online instructional delivery (10:90 and 30:70) were less likely than those with higher levels of face to face delivery to accurately 
predict their final grades. Therefore, it appears that students who self-select into a more online interval level based instructional approach are less likely to attain their expected goals.

Four additional variables of interest were also found to be significant within the logistic regression model. As in the previous model, a student's motivation of flexibility of scheduling as well as the number of courses that they were currently taking had a direct relationship with their expected attainment of a grade. Additionally, students who chose to enroll in the course where the course was a pre-requisite for future courses in criminology/ criminal justice (as a major or minor field of study) also were better able to anticipate and meet the expectations of the course. Those students with a higher current grade point also appear to better assess whether they could meet their own individual goals of success for the class (the letter grade they anticipated).

\section{Implications}

This study offers a glimpse into how student self-selection of instructional delivery and the flexibility of scheduling impacts two measurements of grade attainment. It appears that while instructional delivery is important and significant in determining outcomes, that students who enroll in smaller intervals of online delivery have a higher likelihood of meeting their anticipated goals and attaining better letter grades. As a case study, the findings of the research indicates that while offering choice and selection to students, the more time spent within an online environment (despite offering very comparable lecture based videos), students do not meet their own expectations and attain a lower grade than students who seek more face to face instructional delivery. Even when students initially selected their desired interval option of instructional delivery, ten of the 303 students returned to the safety of more face to face instructional delivery. While offering student's choice in instructional delivery is useful and individualized, it appears that it may have consequences for some students where they do not attain their desired outcome.

\section{References}

1. Becker AS, Cummins M, Davis A, Freeman A, Giesinger HC, et al. (2017) NMC horizon report: 2017 higher Education Edition. Austin: The New Media Consortium.

2. Dziuban CD, Picciano AG, Graham CR, Moskal PD (2016) Conducting research in online and blended learning environments: New pedagogical frontiers. New York: Routledge, Taylor and Francis Group, USA.

3. Picciano AG, Dziuban CD, Grahma CR (2014) Blended learning: Research perspectives (Volume 2). New York, NY: Routledge, USA.

4. World Health Organization (WHO) (2020) ITU-WHO Joint Statement: Unleashing Information Technology to defeat COVID-19.

5. Allen I, Seamon J (2013) Changing Course: 10 years of tracking online education in the United States. Babson Survey Research Group Needham, MA: The Sloan Consortium.

6. Harden RM (2002) Myths and e-learning. Medical Teacher 24(5): 469472.

7. Garrison DR, Anderson T, Archer W (2000) Critical inquiry in a text- based environment: Computer conferencing in higher education. The Internet and Higher Education 2(2-3): 87-105.

8. Garrison DR, Archer W (2003) A community of inquiry framework for online learning. In M. Moore (Ed.), Handbook of distance education. New York: Erlbaum, USA.

9. Barnard L, Lan WY, To YM, Paton VO, Lai SL, et al. (2009) Measuring self-regulation in online and blended learning environments. Internet and Higher Education 12(1): 1-6.

10. Summers J, Waigandt A, Whittakar TA (2005) A Comparison of Student Achievement and Satisfaction in an Online Versus Traditional Face to Face Statistics Class. Innovative Higher Education 29(3): 233-250.

11. Anderson T (2004) Theory and Practice of Online Learning. Canada: AU Press, Athabasca University.

12. Yatrakis P, Simon H (2002) The effect of self-selection on student satisfaction and performance in online classes. International Review of Research in Open and Distance Learning 3(2): 1-8.

13. Colachico D (2007) Developing a sense of community in an online environment. International Journal of Learning 14(1): 161-165.

14. Picciano AG (2002) Beyond student perceptions: Issues of interaction, presence, and performance in an online course. Journal of Asynchronous Learning Networks 6(1).

15. Hill T, Chidamabaram L, Summers JD (2013) A Field Experiment in Blended Learning. Performance Effects of Supplementing the Traditional Classroom Experience with a Web-based Virtual Learning Environment. AMCIS 2013 Proceedings.

16. U.S. Department of Education (2010) Evaluation of evidence-based practices in online learning. Office of Planning, Evaluation, and Policy Development, Washington, D.C.

17. Clement C, Jones K (2007) Blended Learning vs. Traditional Classroom Settings: Assessing Effectiveness and Student Perceptions in an MBA Accounting Course. Journal of Educators Online 4(1): 1-16.

18. Vernadakis N, Giannousi M, Antoniou P, Kioumourtzoglou E (2012) A comparison of student satisfaction between traditional and blended technology course offerings in physical education. Turkish Online Journal of Distance Education 13(1).

19. Tosun S (2015) The Effects of Blended Learning on EFL Students' Vocabulary Enhancement. Procedia - Social and Behavioral Sciences 199: 641-647.

20. Wei Y, Shi Y, Yang HH, Liu J (2017) Blended Learning versus Traditional Learning: A Study on Students' Learning Achievements and Academic Press. International Symposium on Educational Technology 1: 219223.

21. Dziuban C, Graham CR, Moskal PD, Norberg A, Sicilia N (2018) Blended learning: the new normal and emerging technologies. International Journal of Educational Technology in Higher Education 15(3): 1-16.

22. Means B, Toyama Y, Murphy R, Bakia M, Jones K (2010) Evaluation of evidence-based practices in online learning: A meta-analysis and review of online learning. Center for Technology in Learning, U.S. Department of Education.

23. Waldman J, Smith CE (2013) Hybrid Learning in a Canadian College Environment. Toronto: Higher Education Quality Council of Ontario.

24. Cavanaugh JK, Jacquemin SJ (2015) A Large Sample Comparison of Grade Based Student Learning Outcomes in Online vs. Face-to-Face Courses. Online Learning Journal 19(2): 3-8.

25. Boyle T, Bradley C, Chalk P, Jones R, Pickard P (2003) Using blended learning to improve student success rates in learning to program. Journal of Educational Media 28(2/3): 165-178.

26. Kenney J, Newcombe E (2011) Adopting a blended learning approach: 


\section{Annals of Social Sciences \& Management studies}

Challenges, encountered and lessons learned in an action research study. Journal of Asynchronous Learning Networks 15(1): 45-57.

27. Bolsen T, Evans M, Fleming AM (2016) A Comparison of Online and Face-to-Face Approaches to Teaching Introduction to American Government. Journal of Political Science Education 12(3): 302-317.

28. DeNeui DL, Dodge TL (2006) Asynchronous learning networks and student outcomes: The utility of online learning components in hybrid courses. Journal of Instructional Psychology 33(4): 256-259.

29. Kumrow D (2007) Evidence-based strategies of graduate students to achieve success in a hybrid web-based course. Journal of Nursing Education 46(3): 140-145.

30. Senn GJ (2008) Comparison of face-to-face and hybrid delivery of a course that requires technology skills development. Journal of Information Technology Education 7: 267-283.

31. Acton T, Hill S, Scott M (2005) E-education - Keys to Success for Organizations in BLED 2005 Proceedings, Paper 21.

32. Parker T, Nelson P (2009) A comparison of the effectiveness of face to face, online and hybrid formats in a principles of macroeconomics course.

33. Kwak DW, Menezes FM, Sherwood C (2015) Assessing the Impact of Blended Learning on Student Performance. Economic Record 91(292): 91-106.

34. Cao Q Thomas EG, Xue B (2009) The importance of synchronous interaction for student satisfaction with course web sites. Journal of Information Systems Education 20(3): 331-338.

35. Skelton D (2009) Blended is Still Best: Review of Literature and Commentary on Optimal Learning Environments, AMCIS 2009 Proceedings, Paper 615.

36. Roscoe D (2008) Comparing student outcomes in blended and face-toface courses. Completed Research Paper. APSA 2008 Annual Meeting Hynes Convention.

37. York RO (2008) Comparing three modes of instruction in a graduate social work program. Journal of Social Work Education 44(2): 157-172.

38. Farley A, Jain A, Thomson D (2011) Blended learning in finance: Comparing student perceptions of lectures, tutorials and online learning environments across different year levels. Economic Papers: Journal of Applied Economics and Policy 30(1): 99-108.

39. Asarta CJ, Schmidt JR (2015) The choice of reduced seat time in a blended course. Internet and Higher Education 27: 24-31.
40. Rasch T, Schnotz W (2009) Interactive and non-interactive pictures in multimedia learning environments: Effects on learning outcomes and learning efficiency. Learning and Instruction 19: 411-422.

41. Field RM (2005) Favorable conditions for effective and efficient learning in a blended face-to-face (online method), ASCILITE 2005 Proceedings.

42. Loukis E, Georgiou S, Pazalo K (2007) A Value Flow Model for the Evaluation of an E-Learning Service. ECIS 2007 Proceedings, Paper 175.

43. Renner D, et al. (2014) Effectiveness and Efficiency of Blended Learning. A Literature Review. Completed Research Paper. Twentieth Americas Conference on Information Systems. Savannah, GA, pp. 1-13.

44. Twigg CA (2003) Improving learning and reducing costs: New models for online learning. Educause Review 38(5): 28-38.

45. Chen CC, Jones KT (2007) Blended Learning vs. Traditional Classroom Settings: Assessing Effectiveness and Student Perceptions in an MBA Accounting Course. Journal of Educators Online 4(1): 15.

46. Atchley W, Wingenbach G, Akers C (2013) Comparison of course completion and student performances through online and traditional courses international. Review of Research in Open and Distance Learning 14(4): 104-116.

47. Garrison DR, Kanuka H (2004) Blended learning: uncovering its transformative potential in higher education, Internet and Higher Education 7(2): 95-105.

48. Jaggars S, et al. (2013) What we know about online course outcomes. New York: Community College Research Center, Teachers College, Columbia University, USA.

49. Lamport M, Hill R (2012) Impact of Hybrid Instruction on Student Achievement in Post-Secondary Institutions: A Synthetic Review of the Literature. Journal of Instructional Research 1: 49-58.

50. Larson DK, Hsien SC (2009) Comparing student performance: online versus blended versus face-to-face. Journal of Asynchronous Learning Networks 13(1): 31-42.

51. Picciano AG (2009) Blending with purpose: The multimodal model. Journal of Asynchronous Learning Networks 13(1): 7-18.

52. Rivera JC, Rice ML (2002) A comparison of student outcomes and satisfaction between traditional \& web based course offerings. Online Journal of Distance Learning Administration 5(3): 1-12.

53. Rybinski KI, Holzhacker H (2016) Blended Learning Can Improve Student Grades - Narxoz University's Large-Scale Experiment Shows.

\begin{tabular}{|l|}
\hline \multicolumn{1}{|c|}{ Your next submission with Juniper Publishers } \\
will reach you the below assets \\
- Quality Editorial service \\
- Swift Peer Review \\
- Reprints availability \\
- E-prints Service \\
- Manuscript Podcast for convenient understanding \\
- Global attainment for your research \\
- Manuscript accessibility in different formats \\
( Pdf, E-pub, Full Text, Audio) \\
- Unceasing customer service \\
Track the below URL for one-step submission \\
https://juniperpublishers.com/online-submission.php
\end{tabular}

